\title{
Estudo in sílico da atividade biológica por docagem molecular da desloratadina contra esquistossomose
}

\author{
In sílico study of biological activity by molecular docking of desloratadine against \\ 'schistosomiasis
}

\section{Estudio in sílico de la actividad biológica mediante acoplamiento molecular de desloratadina contra la esquistosomiasis}

Joabe Lima Araújo ${ }^{1 *}$, Alice de Oliveira Sousa1, Ruan Sousa Bastos', Gardênia Taveira Santos ${ }^{2}$, Jessé Lima Araújo ${ }^{1}$, Jefferson Almeida Rocha ${ }^{1}$.

\section{RESUMO}

Objetivo: Avaliar a atividade bioativa da desloratadina através de estudos in sílico por docagem molecular em organismos do gênero Schistosoma. Metodologia: Para o estudo foram coletadas proteínas em 3D dos alvos cathepsin B1 (2cb1), purine nucleoside phosphorylase (pnp), thioredoxin glutathione reductase (tgr), e uridine phosphorylase (up) no banco de dados Protein Data Bank (PDB). As análises de docagem foram realizadas pelo software Autodock Tools (ADT) versão ADT 1.5.6. Posteriormente o ligante desloratadina foi obtido no banco de dados PubChem em estrutura 2D e desenhado no programa GaussView 5.0 e otimizado pelo software Gaussian 09W em método Hartree-Fock na base Default Spin/3-21G. O restante dos parâmetros foi definido de acordo com o método padrão. Resultados: De todos os alvos analisados, a desloratadina obteve os melhores resultados nos receptores up e 2cb1 com energias de ligação de -8,49 e $8,35 \mathrm{Kcal}^{\mathrm{mol}} \mathrm{m}^{-1}$ respectivamente. Conclusão: Esses valores demonstram uma boa afinidade molecular em interação dos organismos com a droga desloratadina, além de terem resultados elevados de constante de inibição, demonstrando atividade bioativa da droga antiesquistossomose. Com os presentes resultados in sílico, a droga se torna uma alternativa em estudos bioativos antiesquistossomose, podendo dar continuidade em ensaios in vitro e ex vivo.

Palavras-chave: Docagem molecular, desloratadina, esquistossomose.

\begin{abstract}
Objective: To evaluate the bioactive activity of desloratadine through in silico studies by molecular doping in organisms of the genus Schistosoma. Methods: For the study, 3D proteins from cathepsin B1 (2cb1), purine nucleoside phosphorylase (pnp), thiorredoxin glutathione reductase (tgr), and uridine phosphorylase (up) targets were collected from the Protein Data Bank (PDB) database. The docking tests were performed by Autodock Tools (ADT) software version ADT 1.5.6. Subsequently the desloratadine binder was obtained from the PubChem database in 2D structure and designed in the GaussView 5.0 program and optimized by the Gaussian software 09W in the Hartree-Fock method on the Default Spin/3-2G basis. The rest of the parameters were set according to the standard method. Results: Of all the analyzed targets, desloratadine obtained the best results in the up and $2 \mathrm{cb} 1$ receptors with binding energies of -8.49 and $-8.35 \mathrm{Kcal}^{\mathrm{mol}}{ }^{-1}$ respectively. Conclusion: These values demonstrate a good molecular affinity in the interaction of the organisms with the drug desloratadine, besides having high results of inhibition constant, demonstrating bioactive activity of the drug antischistosomiasis. With the present in silica results, the drug becomes an alternative in antischistosomiasis bioactive studies, being able to give continuity in vitro and ex vivo assays.
\end{abstract}

Key words: Molecular docking, desloratadine, schistosomiasis.

${ }^{1}$ Universidade Federal do Maranhão (UFMA), Grajaú-MA. *E-mail: joabearaujobiotec@gmail.com

2 Universidade Estadual do Maranhão (UEMA), Colinas-MA. 


\section{RESUMEN}

Objetivo: Evaluación la actividad bioactiva de la desloratadina a través de estudios in-sílicos por acoplamiento molecular en organismos del género Schistosoma. Métodos: Para el estudio se recolectar proteínas en 3D de los blancos cathepsin B1 (2cb1), purine nucleoside phosphorylase (pnp), thiorredoxin glutathione reductase (tgr), y uridine phosphorylase (up) en la base de datos Protein Data Bank (PDB). Los análisis de acoplamiento molecular fueron realizados por el software Autodock Tools (ADT) versión ADT 1.5.6. Posteriormente el ligante desloratadina fue obtenido en el banco de datos PubChem en estructura 2D y dibujado en el programa GaussView 5.0 y optimizado por el software Gaussian 09W en el método Hartree-Fock en la base Default Spin / 3-21G. El resto de los parámetros se definió de acuerdo con el método patrón. Resultados: De todos los blancos analizados, la desloratadina obtuvo los mejores resultados en los receptores up y $2 \mathrm{cb} 1 \mathrm{con}$ energías de enlace de $-8,49$ y $-8,35 \mathrm{Kcal}^{-\mathrm{mol}^{-1}}$ respectivamente. Conclusión: Estos valores demuestran una buena afinidad molecular en la interacción de los organismos con la droga desloratadina, además de tener resultados elevados de constante de inhibición, demostrando actividad bioactiva de la droga anti-schistosoma. Con los presentes resultados in-sílicos, la droga se convierte en una alternativa en estudios antiesquistosomiasis, pudiendo dar continuidad en ensayos in vitro y ex vivo.

Palabras clave: Acoplamiento molecular, desloratadina, esquistosomiasis.

\section{INTRODUÇÃO}

A esquistossomose é uma doença infecciosa conhecida comumente no Brasil como barriga d'água, doença do caramujo ou xistosa, causada por um parasita helminto do gênero Schistosoma, endêmica que ocorre nas Américas, Ásia e África. Estima-se que a esquistossomose afeta 200 milhões de pessoas em mais de 74 países. No Brasil ocorre na região Nordeste e no estado de Minas Gerais, sendo relatado cerca de seis milhões de pessoas infectadas pelo parasito (KATZ N e ALMEIDA K, 2003).

No Brasil, foram identificados três tipos de espécie de caramujos responsáveis por abrigar o hospedeiro, são eles: B. glabrata; B. tenagophila; e B. stramínea. Esses moluscos são abundantes em locais de água doce, como por exemplo, barragens, áreas de irrigação, rios, lagos e lagoas (VITORINO RR, et al., 2012).

O ciclo de vida do invertebrado passa por dois hospedeiros, um sendo intermediário e o outro sendo o hospedeiro definitivo. Os ovos do parasita quando eliminado das fezes do hospedeiro humano em locais abundantes de água, rompe liberando uma larva responsável por infectar o hospedeiro intermediário, após seis semanas as larvas ficam livres na água, na forma de cercaria, contaminando todas as pessoas que tiverem contato com essa água, com a penetração do parasito na pele e mucosa, se desenvolvem no organismo humano, após seis semanas, essa infecção pode ser transmitida á outras pessoas pelas fezes contaminadas depositadas em locais inadequados, gerando um ciclo de manifestação da doença (PORDEUS LC, et al., 2008).

Também existe a problemática da resistência dessas cepas aos atuais métodos de tratamento da doença, tendo em vista o desinteresse das indústrias farmacêuticas em buscar novas alternativas de tratamentos antiesquistossomose, pois se trata de uma doença que atinge países subdesenvolvidos e não possuem retornos lucrativos as grandes indústrias farmacêuticas (SAUCHA CVV, et al., 2015).

A desloratadina é considerada como um novo agente para o tratamento de doenças que afetam o sistema respiratório tais como: prurido; prurido ocular; prurido do palato; congestão nasal; renite alérgica sazonal e a urticária crônica e, também por possui uma boa interação com a ligação do receptor $\mathrm{H}_{1} \mathrm{e}$ a seletividade do receptor (CRIADO PR, et al., 2009).

Caracterizada como um anti-histamínico-H1 de segunda geração, a desloratadina também possui ação antialérgica e antiinflamatória, é antagonista não-sedante e não interfere na condução cardíaca. Por obter alta afinidade com os receptores $\mathrm{H} 1$, onde eles possuem meia vida prolongada entre 21-24 horas, podendo ser usado como dose diária (KALPAKLIOGLU F e BACCIOGLU A, 2012).

Essa atividade antiinflamatória o torna atrativo para estudos antibacterianos e antiparasitários, estudos realizando por Cutrona $\mathrm{N}$ et al. (2019) mostra que a desloratadina não apresenta nenhuma atividade anti-S. 
aureus, todavia, quando tratadas com loratadina a bactéria apresentou 8 a 500 vezes mais sensíveis ao referido antibiótico. Esses estudos mostram que a desloratadina, um anti-histamínico-H1 aprovado pela FDA não possui potencial bioativo antibacteriano, porém estudos antiparasitários são necessários para analisar sua ação inibitória contra parasitos. Sendo assim, buscou-se avaliar a atividade bioativa da desloratadina através de estudos in sílico por docagem molecular em organismos do gênero Schistosoma.

\section{MÉTODOLOGIA}

Para o estudo foram coletadas proteínas em 3D dos alvos 2cb1, pnp, tgr, e up no banco de dados que fornece proteínas, PDB. As análises de docagem molecular foram realizadas pelo software Autodock Tools (ADT) versão ADT 1.5.6. Um programa bastante citado na literatura para análises de atividade bioativa (MORRIS GM, et al., 2008). Posteriormente o ligante desloratadina foi obtido no banco de dados PubChem em estrutura 2D e desenhado no programa GaussView 5.0 (DENNINGTON RD, et al., 2008) e otimizado pelo software Gaussian 09W (FRISCH MJ, et al., 2010) em método Hartree-Fock na base Default Spin/3-21G (WONG AT e HARRISON RJ, 1995).

Com o ligante e as macromoléculas preparadas, realizou-se as docagem molecular nas quais foram calculadas após o acréscimo de todos os hidrogênios. Havendo também uma mesclagem de átomos de hidrogênio de proteínas e ligantes apolares. Foi criada uma caixa cúbica de $60 \times 60 \times 60$ pontos com qualidade de resolução com $0,35 \AA$. Tendo também como algoritmo genético o lamarckiano (LGA) (MORRIS GM, et al., 1998). O pseudo-Solis e Wets foi realizado com procura local (SOLIS FJ e WETS RJB, 1981). As simulações consistiram em 100 corridas independentes (RAMOS RM, et al., 2012).

O restante dos parâmetros foi definido de acordo com o método padrão. As análises foram realizadas a partir dos resultados com menor energia de ligação, taxa da constante de inibição (ROCHA JA, et al., 2018).

\section{RESULTADOS E DISCUSSÕES}

Dentre os alvos analisados, constatou-se que a desloratadina obteve a melhor interação com a enzima up, obtendo uma energia de ligação de $-8,49 \mathrm{Kcal}_{\text {. } \mathrm{mol}^{-1}}$ (Tab. 1). Essa interação não formou pontes de hidrogênio, todavia, a interação no sítio de ligação do receptor foi satisfatória. Em comparação com o alcalóide Epiis interagindo com o mesmo receptor, observamos que a desloratadina possui uma afinidade molecular superior a Epiis que tem uma energia de ligação de $-7,68 \mathrm{Kcal}^{\mathrm{mol}}{ }^{-1} \mathrm{com}$ a macromolécula up, essa diferença também se mostra na constante de inibição dos complexos, onde a desloratadina possui uma constante de inibição de 602,87 nM (Tab. 1) e a Epiis com 2,36 $\mu \mathrm{M}$ (ROCHA JA, et al., 2018).

Essa discrepância está relacionada à interação dos dois ligantes com o aminoácido Gln201, que está localizado no sítio ativo do receptor (Fig. 1a), onde a desloratadina possui afinidade molecular muito superior a EPIIS nesse resíduo, ambas interagem no resíduo mais importante da macromolécula (Gln201), a qual, quem possui mais afinidade molecular no resíduo também possuirá maior constante de inibição (NETO AMS, et al., 2016). Também foi comparado com estudos de docagem molecular realizados por Silva MS (2016), onde foi avaliado a atividade biológica da 7-epiclusianoma (7EPI) em uma enzima SOD do S. mansoni que obteve uma energia de ligação de $-4,07 \mathrm{Kcal} \mathrm{mol}^{-1}$ interagindo nos aminoácidos His47, Thr57, Gli60, Ala61, His62, His79, Leu132, Val135, Thr136, Ala139, Gli140 e Arg142, essa baixa interação pode está relacionada com a incompatibilidade do volume da 7-epiclusianona no sítio ativo do receptor, diferentemente do que se observa da desloratadina, que possui alta afinidade molecular com o receptor de S. mansoni.

O complexo desloratadina/2cb1 também obteve uma energia de ligação superior à do complexo epiis/up (ROCHA JA, et al., 2018) com uma taxa de energia de ligação de $-8,35 \mathrm{Kcal}^{\mathrm{mol}}{ }^{-1}$ e também sua constante de inibição foi maior, obtendo $753,56 \mathrm{nM}$ (Tabela 1). Esta interação molecular se torna a mais eficiente dentre todos os alvos analisados neste estudo. $O$ complexo formou uma ligação de hidrogênio no aminoácido Glu124, local onde a força intermolecular do complexo é mais intensa. Os aminoácidos Ala168, Asn122, Asn166, Gly161, Gly169, Lys86, Ser162, Ser87, Thr160, Val123 realizam as interações hidrofóbicas na base do sítio ativo do receptor (Figura 1b). 
Para que haja interação intramolecular entre o ligante e o receptor que formam e mantém estruturas terciárias e quartanárias é essencial uma energia de ligação de 1 a $7 \mathrm{Kcal} \mathrm{mol}^{-1}$, o que define uma interação molecular considerável dos ligantes mencionados anteriormente (desloratadina, epiis e up) possuindo atividade antiesquistossomose (NELSON DL e COX MM, 2011).

Figura 1 - Docagem molecular: a) Desloratadina acoplada no sítio ativo da enzima up e suas interações por ligações hidrofóbicas; b) Desloratadina ligada no sítio ativo da 2cb1 e suas interações por ligações hidrofóbicas e por ponte de hidrogênio entre seus aminoácidos.

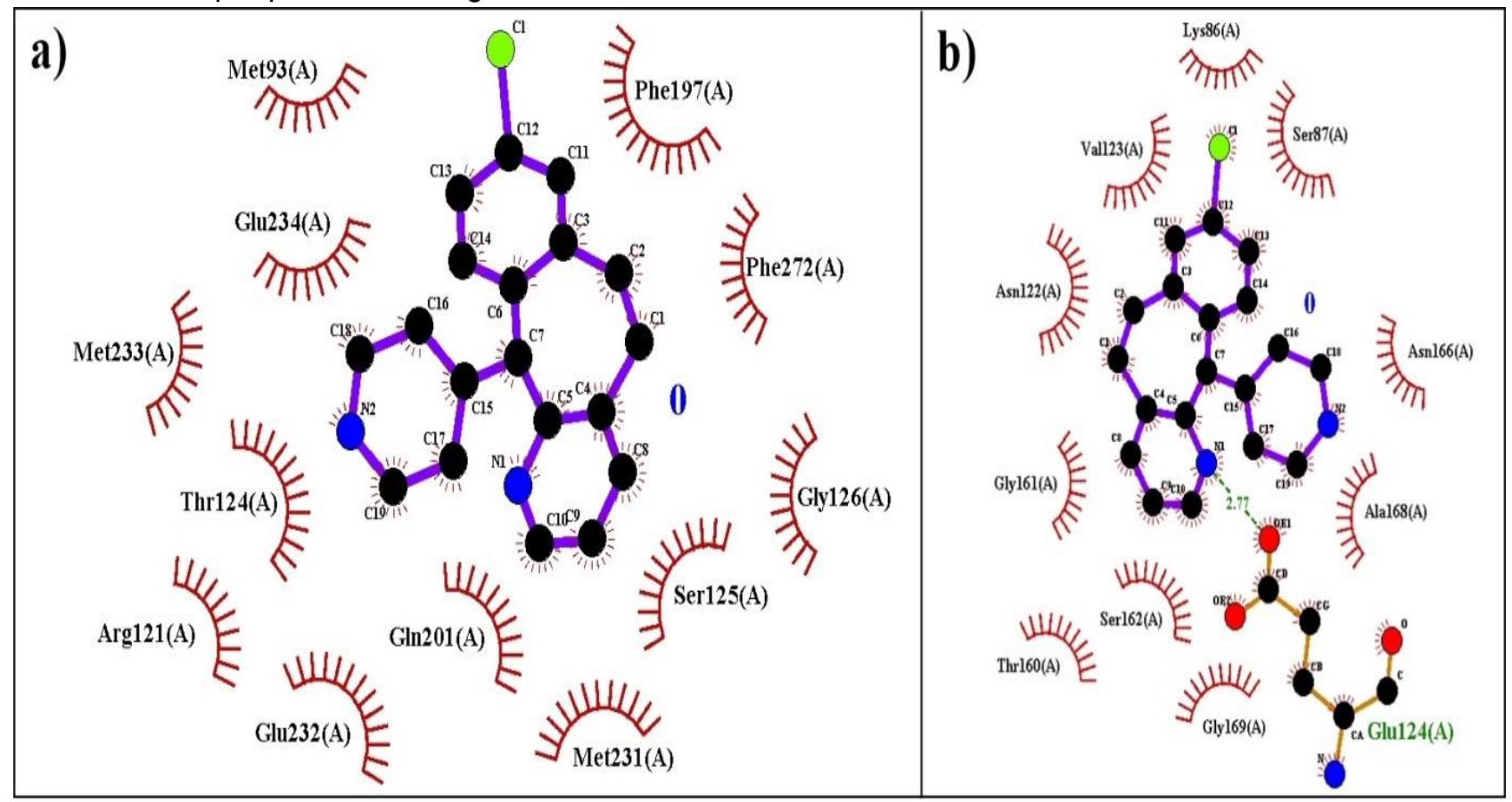

Fonte: autor próprio (2019).

A pnp ancorada ao receptor obteve uma energia de ligação de $-7,65 \mathrm{Kcal} \mathrm{mol}^{-1}$ e uma constante de inibição de 2,49 $\mu \mathrm{M}$ (Tabela 1).

Essa afinidade com o receptor pnp demonstrou possuir mais afinidade molecular do que o alcaloide epiisopiloturina (Epi) interagindo com o mesmo receptor, possuindo uma energia de ligação $-7,18 \mathrm{Kcal} \mathrm{mol}^{-1}$, todavia, essa afinidade molecular superior da desloratadina não demonstra uma constante de inibição superior á da Epi que possui uma constante de inibição $5,46 \mu \mathrm{M}$, isto está relacionado à forte atividade inibitória dos alcalóides contra espécies de esquistossomose (ROCHA JA, et al., 2018).

A docagem molecular do complexo desloratadina/pnp formou uma ligação de hidrogênio no resíduo Tyr202, (Figura 2a) onde a força intermolecular do complexo apresenta-se com maior intensidade. Os aminoácidos que realizam as interações hidrofóbicas estão localizados próximos ao sítio ativo composto pelos aminoácidos Ala118, Ala119, Arg86, Asn245, Gly220, His259, His88, Met221, Tyr202, Tyr90, Val262 ilustrado na Figura 2a.

A docagem molecular do complexo desloratadina/tgr obteve uma energia de ligação de $-7,62 \mathrm{Kcal}^{\mathrm{mol}}{ }^{-1} \mathrm{e}$ uma constante de inibição de 2,62 $\mu \mathrm{M}$ (Tabela 1). Uma afinidade molecular maior em comparação com Epiisopilosina (Epiis) interagindo com a tgr, onde possui uma energia de ligação de $-7,46 \mathrm{Kcal}^{\mathrm{mol}}{ }^{-1}$ e uma constante de inibição de 3,4 $\mu \mathrm{M}$ (ROCHA JA, et al., 2018).

Como no caso anterior, observamos que a atividade inibitória dos alcalóides são superiores a da desloratadina, mesmo o fármaco possuindo melhor afinidade molecular com o receptor tgr, isso está relacionado às interações dos alcalóides Epi e Epiis no resíduo Tyr296, que é o aminoácido mais ativo na interação molecular dos alcalóides com a tgr e também observada na literatura (MAFUD AC, et al., 2018). 
A tgr é uma flavoenzima quimérica ativa no processo de desintoxicação e importante para a sobrevivência do parasita no organismo do hospedeiro, por isso ela se torna um alvo atrativo para estudos antiesquistossomose (ANGELUCCI F, et al., 2008). O complexo desloratadina/tgr resultou em uma ligação de hidrogênio no aminoácido Val157 (Figura 2b).

Figura 2 - Docagem molecular: a) Desloratadina acoplada no sítio ativo da enzima pnp e suas interações por ligações hidrofóbicas e por pontes de hidrogênio; b) Desloratadina ligada no sítio ativo da tgr e sua interação por ponte de hidrogênio entre seus aminoácidos.

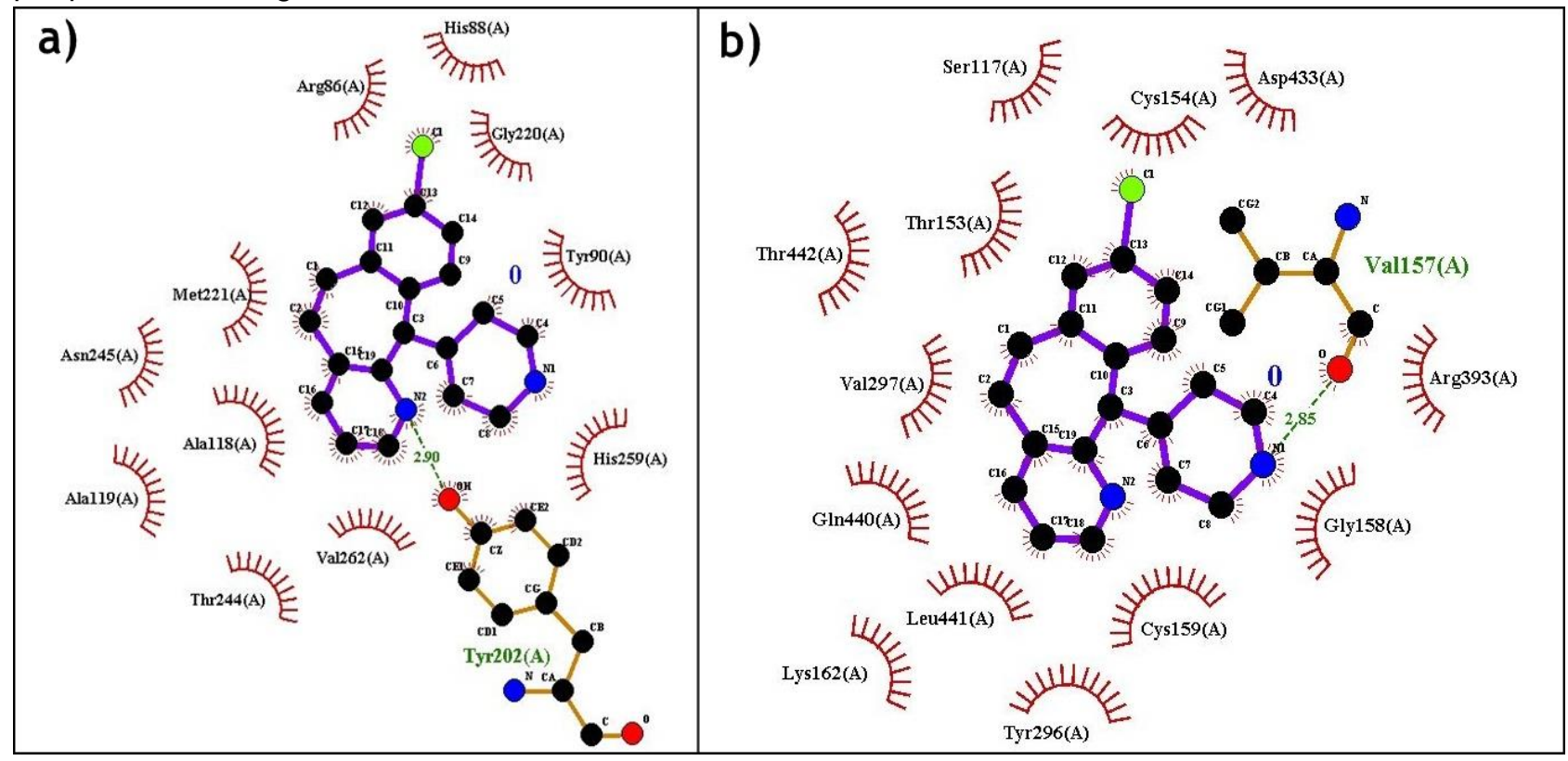

Fonte: autor próprio (2019).

Tabela 1 - Parâmetros de afinidade molecular entre uridine phosphorylase (up), cathepsin B1 (2cb1), purine nucleoside phosphorylase (pnp), e thioredoxin glutathione reductase (tgr) com o inibidor Desloratadina.

\begin{tabular}{|c|c|c|c|c|}
\hline $\begin{array}{c}\text { Complexo } \\
\text { (proteína-ligante) }\end{array}$ & $\begin{array}{c}\mathrm{G}_{\text {bind }}{ }^{\mathrm{a}} \\
\left(\mathrm{kcal}^{\left.-\mathrm{mol}^{-1}\right)}\right.\end{array}$ & $\begin{array}{l}\mathbf{K i}^{\mathbf{b}} \\
(\mu \mathrm{M})\end{array}$ & $\begin{array}{c}\text { Aminoácidos que } \\
\text { Interagem Através de } \\
\text { Ligações de Hidrogênio }\end{array}$ & $\begin{array}{l}\text { Aminoácidos que Fazem } \\
\text { Interações Hidrofóbicas }\end{array}$ \\
\hline Desloratadina/up & $-8,49$ & $\begin{array}{l}602,87 \\
\mathrm{nM}\end{array}$ & - & $\begin{array}{l}\text { Arg121, Gln201, Glu232, } \\
\text { Glu234, Gly126, Met231, } \\
\text { Met233, Met93, Phe197, } \\
\text { Phe272, Ser125 Thr124 }\end{array}$ \\
\hline Desloratadina/2cb1 & $-8,35$ & $\begin{array}{l}753,56 \\
\mathrm{nM}\end{array}$ & Glu124 & $\begin{array}{lrr}\text { Ala168, } & \text { Asn122, } & \text { Asn166, } \\
\text { Gly161, } & \text { Gly169, } & \text { Lys86, } \\
\text { Ser162, } & \text { Ser87, } & \text { Thr160, } \\
\text { Val123 } & & \\
\end{array}$ \\
\hline Desloratadina/pnp & $-7,65$ & $\begin{array}{l}2,49 \\
\mu \mathrm{M}\end{array}$ & Tyr202 & $\begin{array}{lrr}\text { Ala118, } & \text { Ala119, } & \text { Arg86, } \\
\text { Asn245, Gly220, } & \text { His259, } \\
\text { His88, Met221, } & \text { Tyr90, } \\
\text { Val262, Thr244 } & \\
\end{array}$ \\
\hline Desloratadina/tgr & $-7,62$ & $\begin{array}{l}2,62 \\
\mu \mathrm{M}\end{array}$ & Val157 & $\begin{array}{lll}\text { Arg393, Asp433, } & \text { Cys154, } \\
\text { Cys159, Gln440, Gly158, } \\
\text { Leu441, Lys162, Ser117, } \\
\text { Thr153, Thr442, } \\
\text { Val297296, }\end{array}$ \\
\hline
\end{tabular}

Fonte: autor próprio (2019). 
Frente aos resultados apresentados e as problemáticas de cepas de schistosoma mansoni estarem cada vez mais resistentes a antibióticos, chegando a infectar cerca de 200 milhões de pessoas no mundo por ano (KATZ N e ALMEIDA K, 2003), a uma necessidade de novas alternativas no tratamento desta doença, uma vez que os atuais medicamentos estão menos eficazes, além de provocarem diversos efeitos colaterais às pessoas que se submetem ao tratamento, onde a desloratadina se apresenta como uma possível alternativa para novos tratamento anti-esquistossomose, apresentando afinidade molecular para todos os alvos de schistosoma mansoni realizado neste estudo, além de possuírem constantes de inibições elevadas, se apresentando promissora em analises antiparasitária diferentemente do que foi apresentado em analises antibacteriana realizadas por Cutrona $\mathrm{N}$ et al. (2019).

\section{CONSIDERAÇÕES FINAIS}

De todos os alvos analisados, a desloratadina obteve os melhores resultados nos receptores putative uridine phosphorylase e cathepsin B1 com energias de ligação de $-8,49$ e - $8,35 \mathrm{Kcal}_{\text {.mol }}{ }^{-1}$ respectivamente. Esses valores demonstram uma boa afinidade molecular em interação dos organismos com a droga desloratadina, além de terem resultados elevados de constante de inibição, demonstrando atividade bioativa da droga antiesquistossomose. Com os presentes resultados in sílico, a droga se torna uma alternativa em estudos de drogas antiesquistossomose, podendo dar continuidade em ensaios in vitro e ex vivo.

\section{REFERÊNCIAS}

1. ANGELUCCI F, et al. Glutathione reductase and thioredoxin reductase at the crossroad: the structure of Schistosoma mansoni thioredoxin glutathione reductase. Proteins: Structure, Function, and Bioinformatics, 2008; 72(3): 936-945.

2. CRIADO PR, et al. Histamina, receptores de histamina e anti-histamínicos: novos conceitos. An Bras Dermatol, 2010; 85(2): 195-210.

3. CUTRONA N, et al. From antihistamine to anti-infective: Loratadine inhibits regulatory PASTA kinases in Staphylococci to reduce biofilm formation and potentiate $\beta$-lactam antibiotics and vancomycin in resistant strains of $S$. aureus. ACS infectious diseases, 2019.

4. DENNINGTON RD, et al. GaussView, v. 5.0.8, Semicchem, Inc.: Shawnee KS, 2008.

5. FRISCH MJ, et al. Petersson., GA et al. Gaussian09, Rev. C. 01; Gaussian. Inc.: Wallingford, CT, 2010.

6. KATZ N, ALMEIDA K. Esquistossomose, xistosa, barriga d'água. Ciência e Cultura, 2003; 55(1): 38-43.

7. KALPAKLIOGLU F, BACCIOGLU A. Efficacy and safety of $\mathrm{H} 1$-antihistamines: an update. Anti-Inflammatory \& Anti-Allergy Agents in Medicinal Chemistry (Formerly Current Medicinal Chemistry-Anti-Inflammatory and Anti-Allergy Agents), 2012; 11(3): 230-237.

8. MAFUD AC, et al. Antiparasitic, structural, pharmacokinetic, and toxicological properties of riparin derivatives. Toxicology in Vitro, 2018; 50:1-10.

9. MORRIS GM, et al. Using autodock for ligand-receptor docking. Current protocols in bioinformatics, 2008; 24(1): 8-14.

10. MORRIS GM, et al. Automated docking using a Lamarckian genetic algorithm and an empirical binding free energy function. Journal of computational chemistry, 1998; 19(14): 1639-1662.

11. NETO AMS, et al. Analysis of two Schistosoma mansoni uridine phosphorylases isoforms suggests the emergence of a protein with a non-canonical function. Biochimie, 2016; 125:12-22.

12. NELSON DL, COX MM. Princípios de Bioquímica. $5^{\underline{a}}$ ed. Porto Alegre: ARTMED, 2011; 43P.

13. PORDEUS LC, et al. A ocorrência das formas aguda e crônica da esquistossomose mansônica no Brasil no período de 1997 a 2006: uma revisão de literatura. Epidemiologia e Serviços de Saúde, 2008; 17(3): 163-175.

14. RAMOS RM, et al. Interaction of wild type, G68R and L125M isoforms of the arylamine-N-acetyltransferase from Mycobacterium tuberculosis with isoniazid: a computational study on a new possible mechanism of resistance. Journal of molecular modeling, 2012; 18(9): 4013-4024.

15. ROCHA JA, et al. Computational quantum chemistry, molecular docking, and ADMET predictions of imidazole alkaloids of Pilocarpus microphyllus with schistosomicidal properties. PloS one, 2018; 13(6): e0198476.

16. SAUCHA CVV, et al. Condições de saneamento básico em áreas hiperendêmicas para esquistossomose no estado de Pernambuco em 2012. Epidemiologia e Serviços de Saúde, 2015; 24:497-506.

17. SILVA MS. Análise de atividade esquistossomicida da 7-epiclusianona utilizando ferramentas bioquímicas e moleculares. Dissertação (Mestrado em Ciências Farmacêuticas). Universidade Federal de Alfenas, Unifal, 2016; 57-64 p.

18. SOLIS FJ, WETS RJB. Minimization by random search techniques. Mathematics of operations research, 1981; 6(1): 19-30.

19. VITORINO RR, et al. Esquistossomose mansônica: diagnóstico, tratamento, epidemiologia, profilaxia e controle. Rev Soc Bras Clin Med, 2012; 10(1): 39-45.

20. WONG AT e HARRISON RJ. Approaches to large-scale parallel self-consistent field calculations. Journal of computational chemistry, 1995; 16(10): 1291-1300. 